\section{IMPACT OF FEEDWATER SALINITY ON ENERGY REQUIREMENTS OF A SMALL-SCALE MEMBRANE FILTRATION SYSTEM}

\author{
B.S. Richards ${ }^{1,2^{*}}$, L. Masson ${ }^{3}$, A.I. Schäfer ${ }^{4,5}$
}

${ }^{1}$ School of Engineering and Physical Sciences, Heriot-Watt University, Edinburgh, EH14 4AS, United Kingdom ${ }^{2}$ Centre for Sustainable Energy Systems, Australian National University, Canberra, ACT 0200, Australia ESIGEC, Université de Savoie, Le Bourget du Lac 73376, France

${ }^{4}$ Environmental Engineering, University of Wollongong, Wollongong NSW 2522, Australia ${ }^{5}$ School of Engineering and Electronics, The University of Edinburgh, Edinburgh, EH9 3JL, United Kingdom

\section{ABSTRACT}

Many remote communities in both developed and developing countries lack electricity and clean drinking water. One solution, for such communities that rely on brackish groundwater, is a photovoltaic (PV) powered hybrid ultrafiltration (UF) / nanofiltration (NF) or reverse osmosis (RO) membrane filtration system. The system prototype described here can produce between $150-280$ litres of clean water for each peak sunshine hour, depending on the salinity of the fect (1) specific energy consumption (SEC) for achieving drinking water quality with a salinity of less than $0.5 \mathrm{~g} / \mathrm{L}$ TDS from $1,2.5$ and $5 \mathrm{~g} / \mathrm{L}$ salinity feedwater was $1.1,1.8$ and $2.6 \mathrm{kWh} / \mathrm{m}^{3}$, respectively. Slightly higher feedwaters $(7.5 \mathrm{~g} / \mathrm{L})$ can be treated with one of the membranes tested, and as long as sufficient power is available for providing an adequate transmembrane pressure. Higher salinities cannot e treated effectively with the current system due to pressure limitations. Energy recovery would need to be investigated in order to achieve a competitive SEC for such high salinity feedwaters.

Keywords: photovoltaic, solar energy, desalination, membranes, nanofiltration and reverse osmosis, submerged ultrafiltration pretreatment.

\section{INTRODUCTION}

Small-scale membrane filtration systems that are able to be powered from a renewable energy source are of great interest for remote communities in both developed and developing countries. This is underpinned by the fact that an estimated 1.3 billion people do not have access to clean drinking water, while a further 2 billion are living without electricity (UNDP access to clean drinking water, while a further 2 billion are living without electricity (UNDP
1998). The overlap between these two groups - living with neither electricity nor clean water 1998). The overlap between these two groups - living with neither electricity nor clean water
- has been estimated at 1 billion people, or $17 \%$ of the world's population (Parodi et al. 2000).

The research presented here is an initial effort to characterise the range of feedwater salinities that can be effectively treated using a small-scale membrane filtration system using a variety of nanofiltration (NF) and reverse osmosis (RO) membranes. The hybrid system described here is novel in that it includes an ultrafiltration (UF) pre-treatment stage in order to reduce problems of membrane fouling that have occured in other small-scale desalination systems plicability such a sinile system to be powered via a renewable energy source - in this case photovoltaic (PV) solar energy - has been demonstrated during a six week field trip in Central Australia (Schäfer et al. 2007). While other small-scale PV-

* Corresponding author: Bryce Richards. Email: B.S.Richards@hw.ac.uk, tel: +44 131451 3614, fax: +44 131 4513129 powered systems have been presented in the literature and even commercialised (Laborde et al. 2001, Alajlan and Smiai, 1996, Keefer et al. 1985, Mathew et al. 2000, Weiner et al. 2001, Al Sulaeimani and Nair 2000), until now results reporting the performance of such smallscale systems over a wide range of feedwater salinities, ranging from $1 \mathrm{~g} / \mathrm{L}$ total dissolved solids (TDS) to 35 g/L TDS have not been presented. The application of this technology to tem an required in various emergency situations demands an understanding of system performance over a range of water supplies as opposed to stationary installations where variations in feed water do occur but not over such a wide range. However, situations where conditions have changed drastically due to a disaster have also occurred, for example, following a tsunami that has lead to seawater intrusion into the normally brackish groundwater (Vrba and Verhagen 2006).

Furthermore, correlations between the experimental results presented here and the modelling results from the literature (Laborde et al. 2001) can be drawn. Of particular importance when considering renewable energy as a source of power is the specific energy consumption (SEC: produce $1 \mathrm{~m}^{3}$ of clean drinking water. This SEC translates directly into the requires solar panel area and hence capital cost, while in non-renewable energy powered systems energy would be a operating cost. Further performance parameters of interest that are presented in this paper include flux and permeate salinity, recovery and retention, as well as power consumption.

The aim of this project was to investigate the applicability of using photovoltaic (PV) modules for powering a RO desalination system. PV was chosen given its propensity to operate well for over 20 years in harsh, remote environments. The majority of PV-powered RO systems are designed to desalinate seawater, which has a salinity of about $35 \mathrm{~g} / \mathrm{L}$ TDS, and therefore require very high pressure $(40-80 \mathrm{bar})$ pumps to overcome the natural osmotic pressure of the feedwater. However, a synergistic relationship often exists between lack of fresh surface water (e.g. rivers, rainfall) and the abundance of both solar irradiation and groundwater that is of marginal $(0.5-1.5 \mathrm{~g} / \mathrm{L}$ TDS) or brackish $(1.5-5.0 \mathrm{~g} / \mathrm{L}$ TDS $)$ quality (Schäfer et al. 2007). Therefore, the objective was to determine the performance of PVmembrane system that is designed to desalinate groundwater of marginal and brackish quality without the need for electrical storage (batteries). Due to fluctuations in solar radiation, ROSI needs to be tested over a wide range of operating conditions, and this was performed in the laboratory with water of widely varying salinity.

\section{EQUIPMENT}

Since 2001, this project has developed five prototypes and is in progress of commercialization (Schäfer and Richards 2007). The system described here is from the third project stage prior to the development of a customized pump, which is often the weakest link in such technologies. Figure 1 shows a schematic diagram of the components in the small-scale hybrid membrane desalination system.

\subsection{Power generation and electronics}

Electricity can either be produced by the PV array or converted to DC from an AC power source such as electricity grid or a backup generator providing $230 \mathrm{~V}_{\mathrm{AC}}$ power. In this paper the pump was powered by DC power supply to provide a stable energy source for experiments, however the system has also been powered by PV panels (Schäfer et al. 2007).

\subsection{Pumps}

Initially, feedwater needs to be pumped from the groundwater bore into a 200-litre feedwater tank. Both the bore and its associated pump are assumed to already exist at the intended 
location and the energy requirements of such a pump are not included in the analysis in this paper. Six ultrafiltration (UF) submerged membrane modules (see below) are immersed in the feed tank and water is drawn through the membranes by the progressive cavity pump shown in Figure 1 (LF502, Mono Pumps, Australia). This pump, which also subsequently feeds the water through the NF or low pressure RO membranes, is of the same type that has by the length of the rotor and stator, while the flow rate is determined by the motor speed. The LF502 pump is capable of high pressures (up to 24 bar maximum) and delivers a maximum flow of $470 \mathrm{~L} / \mathrm{h}$ at 15 bar pressure. The pressure was varied from 4 to 15 bar in 1 bar increments at constant feed flow, which naturally results in a increase in recovery and power consumption.

\subsection{Membranes}

The six UF membrane modules are connected in parallel and submerged in the feedwater tank to form the pre-treatment system (see Figure 2a). A gentle suction (about 0.5 bar) is applied to draw the permeate through the hollow fibres, which have a nominal pore size of $0.04 \mu \mathrm{m}$ (Côté et al. 2001). Figure 2(b) shows of photo of the third prototype of the small-scale hybrid membrane treatment system, prior to its mounting onto a trailer equipped with PV panels and a solar tracker (Schäfer et al. 2007).

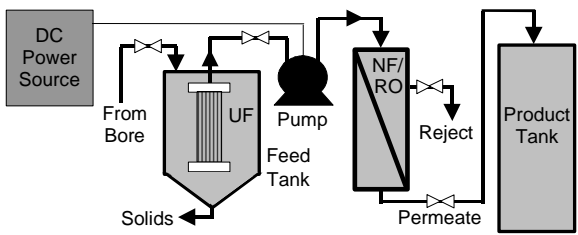

Figure 1. Schematic diagram of the small-scale UF/NF hybrid membrane desalination system that is designed to be powered by a renewable energy source. The thick lines are water flows, while the thin lines are electrical connections.
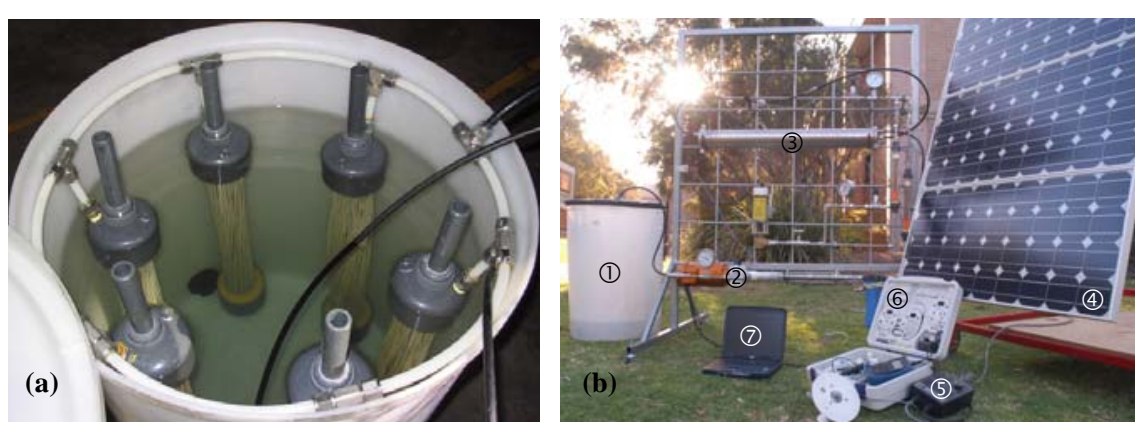

Figure 2(a) Six Zenon ZeeWeed 10 UF pre-treatment membranes connected in parallel; (b) Components of the third prototype of the UF/NF hybrid membrane desalination system: (1) UF membranes in feed tank; (2) LF502 pump; (3) NF membrane; (4) PV array; (5) motor UF membranes in feed tank; (2) LF502 pump; (3) NF membrane; (4) $P V$ array; (5) motor
controller; (6) meters for water ( $\mathrm{pH}$, conductivity, and temperature) and solar radiation measurements; and 8 computer for data acquisition.
Experiments were performed with three different low-pressure NF/RO membranes (all 4" in diameter and 40" in length) to identify the optimum membrane choice for different feedwater salinities: Dow Filmtec NF90 and BW30 (Dow Filmtec Membranes 2007a, 2007b), and Koch (Fluid Systems) TFC 4920-S (Koch Membrane Systems 2007). All membranes have a maximum flow of $320-380 \mathrm{~L} / \mathrm{h}$, and the recommended operating pressure of the two Filmtec membranes was $15.5 \mathrm{bar}$, while the Fluid Systems membrane was 5.5 bar. According to the manufacturers the NF90, BW30 and TFC 4920-S membranes are able to retain up to $97 \%$, $99.5 \%$ and $85 \%$ of sodium chloride $(\mathrm{NaCl})$, respectively.

There are several advantages to the hybrid UF and NF/RO membrane configuration:

There are several advantages to the hybrid UF and NF/RO membrane particulates can sink to
1. Since the UF membrane is suspended in the feed tank, heavier pon the bottom of the tank rather than accumulating on the membrane surface. The feed tank can be periodically emptied to remove any solids.

2. By effectively removing all turbidity and bacteria, the UF membranes assist in extending the life of the NF/RO membrane by supplying it with clean water that contains only sats and trace elements, thus reducing maintengice requiements, foul contains only sats, and water cos

3. The UF membrane is able to remove bacteria, cysts, most viruses and other microbiological contents. Thus, for the treatment of low-salinity surface waters where disinfection is the main concern - such as a polluted river - the UF membrane alone may be sufficient. Where desalination is required, the UF and NF/RO membranes are a second barrier to pathogens and thois stage effectively removes all viruses.

4. The pressure drop across the UF membrane is small and the same pump that delivers water to the NF/RO module can be used to suck water through the UF module.

5. The UF membranes can be cleaned quite simply, either by a backflush (flow reversal) or by the injection of compressed air at the base of the membranes in order to scour the membrane surface, both requiring further investigations. In terms of chemical cleaning household bleach can be used which is readily available and reasonably cheap.

6. Where applicable, a NF membrane that is designed to operate at lower pressures (5-10 bar) than a RO membrane can be used to reduce the power requirements of the system. However, the salt rejection of the NF membrane is likely to only be sufficient to achieve clean drinking water from brackish water sources.

Further advantages of a hybrid UF and NF/RO membrane configuration were summarized by Redondo (2001) as being: and lower whole-of-life pre-treatment costs compared to conventional pre-treatment.

\subsection{Data Acquisition}

Samples were collected at each interval from the feed tank, UF permeate, NF/RO permeate and NF/RO concentrate. Turbidity, $\mathrm{pH}$, temperature, and conductivity were measured immediately, while $25 \mathrm{~mL}$ of sample was collected for later elemental analysis. Permeate flux, voltage and current were also measured. Both permeate and concentrate were recirculated into the feed tank.

\section{RESULTS}

The selection of an appropriate RO or NF membrane depends on the feedwater quality and targeted contaminants that have to be retained. This paper explores a wide range of feedwater salinities, ranging from $1 \mathrm{~g} / \mathrm{L}-35 \mathrm{~g} / \mathrm{L}$ TDS, in essence the range from surface to seawater. Systematic experiments were performed under different conditions to evalua the Syste performance of ROSI using the three different $\mathrm{NF} / \mathrm{RO}$ membranes with an emphasis on specific energy consumption. The feedwater used for all expeninents in this section was $200 \mathrm{~L}$ of tap water with the addition of $1,2.5,5,7.5,10,15,25$ or $35 \mathrm{~g} / \mathrm{L}$ TDS of swimming 
pool salt, to simulate marginal, brackish and saline water. The first set of experiments consisted of maintaining the feed flow rate constant at $150 \mathrm{~L} / \mathrm{h}$ and running the system with different operating pressure $(4-15 \mathrm{bar})$ and salt concentrations ( 1 to $35 \mathrm{~g} / \mathrm{L})$. The second set of experiments monitored the performance of the system again, but this time operating at a constant operating pressure $(10 \mathrm{bar})$ and a variable feed flow rate of $150-500 \mathrm{~L} / \mathrm{h}$ and TDS. Those variations of flowrate and pressure simulate the energy fluctuations in such a system when operated with renewable energy that is linked directly to the pump (in absence of battery or converter)

Figure 3 plots the performance of ROSI with the Filmtec BW30 membrane, which is described by the manufacturer as a RO element for desalination of brackish water. Several trends are observed in the flux (Figure 3a) performance as a function of pressure. Firstly, flux increases linearly with the applied pressure for all salt concentrations at low operating pressures. However, at high pressures there is a slight departure from linearity, which can be explained with concentration polarisation (Masson et al. 2005). Secondly, the permeate flux is also shown to derease with incieasing feedwater salinity. This is due to higher sat polaizaion and halt , and pressures, which work against the applied pressures, and hence the effective transmembrane pressure is smaller and provides a smaller driving force across the membrane.

The recovery (Figure 3b) is shown to increase as a function of pressure and to decrease with increasing feedwater salinity, as expected. The retention of the BW30 membrane (Figure 3c) of all feedwater salinities less than $5 \mathrm{~g} / \mathrm{L}$ TDS is greater than $90 \%$. This results in a permeate salinity (Figure 3d) that meets the Australian Drinking Water Guideline (ADWG) value of $500 \mathrm{mg} / \mathrm{L}$ TDS (NHMRC, 2004). For higher salinity feedwaters retention declines due to the pressure limitation and concentration polarization and in consequence the ADWG can no longer be complied with. Feedwaters of $7.5 \mathrm{~g} / \mathrm{L}$ require a pressure of at least $8 \mathrm{bar}$ to $\mathrm{produce}$ a drinkable product.

The progressive cavity pump used in the system has a linear relationship between transmembrane pressure and power consumption (Figure 3e). Once the power consumption and flux are known, then the SEC (Figure 3f) can be calculated as the ratio of these two values (units: $\mathrm{kWh} / \mathrm{m}^{3}$ ). The SEC for the BW30 membrane shows a minimum at low salinity feedwaters due to the lower osmotic pressure and decreases with increasing transmembrane pressures due to higher flux and hence increased recovery. The minimum SEC for $2.5 \mathrm{~g} / \mathrm{L}$ TDS is $21 \mathrm{kWh} / \mathrm{m}^{3}$ at a pressure of $15 \mathrm{bar}$ and a flow of $280 \mathrm{~L} / \mathrm{h}$ and producing a L TDS feedwater had a SEC (7.5 $290 \mathrm{~L} / \mathrm{h}$ and producing a flux of $19.5 \mathrm{~m} \mathrm{~m}^{-2} \mathrm{~s}^{-1}$. Higher salinity feedwate (7.5 g/L TDS) can be treated as long as at least $300 \mathrm{~W}$ of power is available to provide a transmembrane pressure of at least 8 bar, however the SEC is increasing significantly due to the limited flux at higher salinities.
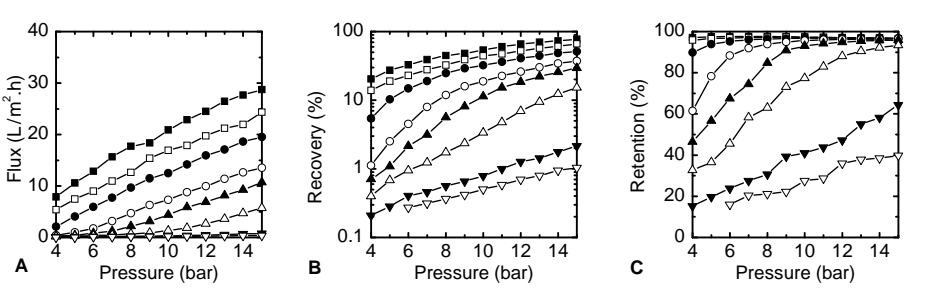

Feedwater Salinity

$-1.0 \mathrm{~g} / \mathrm{L}$
$-\square-2.5 \mathrm{~g} / \mathrm{L}$

Pressure (bar)
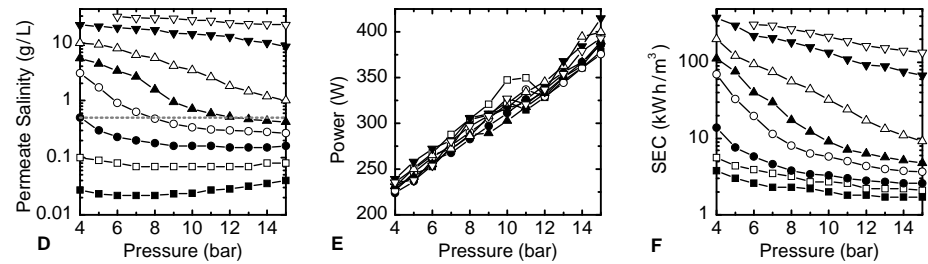

$-0-7.5 \mathrm{~g} / \mathrm{L}$

$-\Delta-10 \mathrm{~g} / \mathrm{L}$
$-\Delta-15 \mathrm{~L} / \mathrm{L}$

Figure 3. Performance of ROSI system with UF pre-filters and BW30 membrane for a wide range of feedwater salinities: a) flux; b) recovery; c) retention; $d$ ) the resulting salinity in the permeate stream; e) power; and ff specific energy consumption. The Australian Drinking Water Guideline (ADWG) of $0.5 \mathrm{~g} / \mathrm{L}$ TDS is also plotted in grey in Figure 3d.

Figure 4 shows the performance of the system with the Filmtec NF90 nanofiltration membrane. The trends observed for the NF90 membrane are similar to those for the BW30 membrane. Notable differences are the increased flux (Figure 4a), and hence increased recovery (Figure $4 \mathrm{~b}$ ), reduced retention at high salinities (Figure 4c), and hence increased permeate salinity (Figure 4d) and, due to the higher productivity at identical pressure, reduced SEC (Figure 4f). When equipped with the NF90 membrane, the system can still satisfactorily desalinate feedwaters with salinities of up to $5 \mathrm{~g} / \mathrm{L}$ TDS, but a water of $7.5 \mathrm{~g} / \mathrm{L}$ can no longer be treated. The SEC $\left(2.2 \mathrm{kWh} / \mathrm{m}^{3}\right.$ at a pressure of $15 \mathrm{bar}$ and a flow of $276 \mathrm{~L} / \mathrm{h}$ and producing a flux of $\left.25.4 \mathrm{~m}^{3} \mathrm{~m}^{-2} \mathrm{~s}^{-1}\right)$ than for the BW30 membrane $\left(2.6 \mathrm{kWh} / \mathrm{m}^{3}\right)$ which reflects a saving of $20 \%$ due to membrane choice. 
Richards, B.S. ; Masson, L. ; Schäfer, A.I. ; (2009) Impact of Feedwater Salinity on Energy Requirements of a Small-Scale Membrane Filtration System, In: AppropriateTechnologies for Environmental Protection in the Developing World, Yanful, E. (Ed), Springer Science + Business Media, Chapter 3, 123-138.
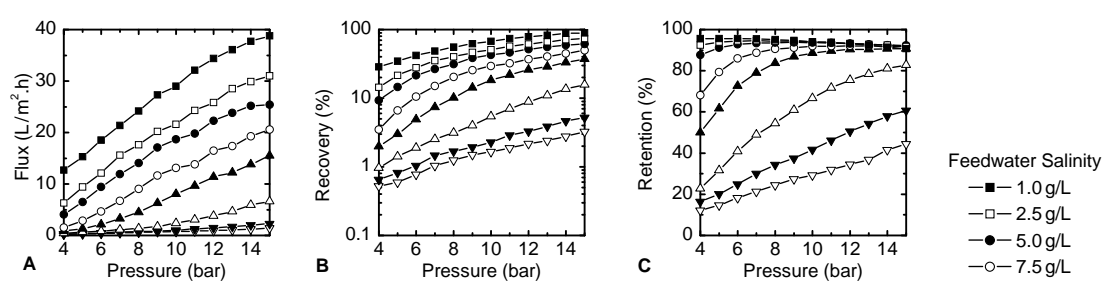

$-1.09 / \mathrm{L}$

A $\begin{gathered}6 \\ \text { Pressure (bar) }\end{gathered}$
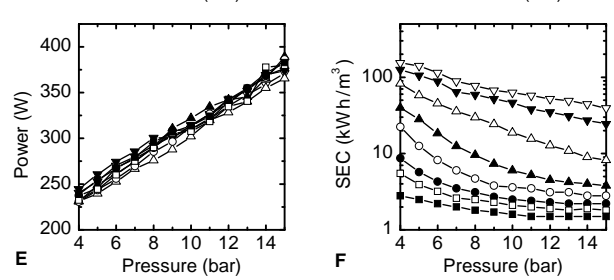

$-0-7.5 \mathrm{~g} / \mathrm{L}$

$-\Delta-10 \mathrm{~g} / \mathrm{L}$
$-\Delta-15 \mathrm{~g} / \mathrm{L}$

$\nabla-25 g$

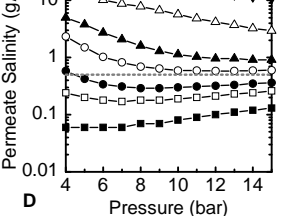

$\mathrm{E}$

6
Pressure (bar)

Figure 4. Performance of ROSI system with UF pre-filters and NF90 membrane for a wide range of feedwater salinities: $a$ ) flux; b) recovery; c) retention; d) the resulting salinity in the permeate stream; e) power; and f) specific energy consumption. The ADWG of $0.5 \mathrm{~g} / \mathrm{L}$ TDS is also plotted in grey in Figure $4 d$.

The trends observed in system performance with the NF90 membrane become much more obvious with the experiments conducted with the Fluid Systems TFC-4920-S "softening" membrane (Figure 5). The flux (Figure 5a) and recovery (Figure 5b) are both significantly higher, however so is the permeate salinity (Figure $5 \mathrm{~d}$ ). This results in the system only being able to meet ADWG values for feedwater salinities of $1 \mathrm{~g} / \mathrm{L}$ TDS which makes this an ideal surface water membrane. The SEC of such waters is then only $1.2 \mathrm{kWh} / \mathrm{m}^{3}$ at a pressure of 13 bar and a flow of $290 \mathrm{~L} / \mathrm{h}$ and producing a flux of $39.2 \mathrm{~m}^{3} \mathrm{~m}^{-2} \mathrm{~s}^{-1}$.
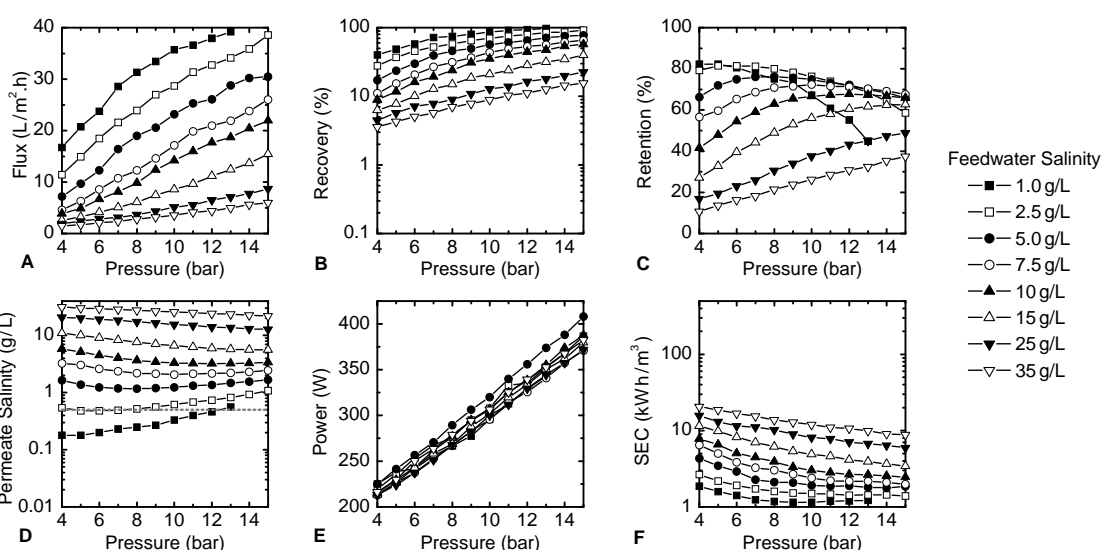

$-0-7.5 \mathrm{~g} / \mathrm{L}$

$-\mathbf{- 1 0 g / L}$

$-\nabla-25 g / L$
$-\nabla-35 g / L$

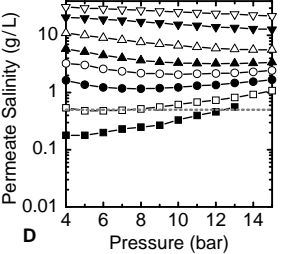

Pressure (bar)

Figure 5. Performance of ROSI system with UF pre-filters and TFC-4920-S membrane for a wide range of feedwater salinities: a) flux; b) recovery; c) retention; d) the resulting salinity in the permeate stream; e) power; and ff specific energy consumption. The ADWG of $0.5 \mathrm{~g} / \mathrm{L}$ TDS is also plotted in grey in Figure $5 d$.
For the experiments where the ROSI system was operated at a constant pressure of 10 bar and feedwater salinity of $5 \mathrm{~g} / \mathrm{L}$ TDS, the performance of all three membranes is plotted in Figure $6(\mathrm{a}-\mathrm{f})$ as a function of feedwater flow.
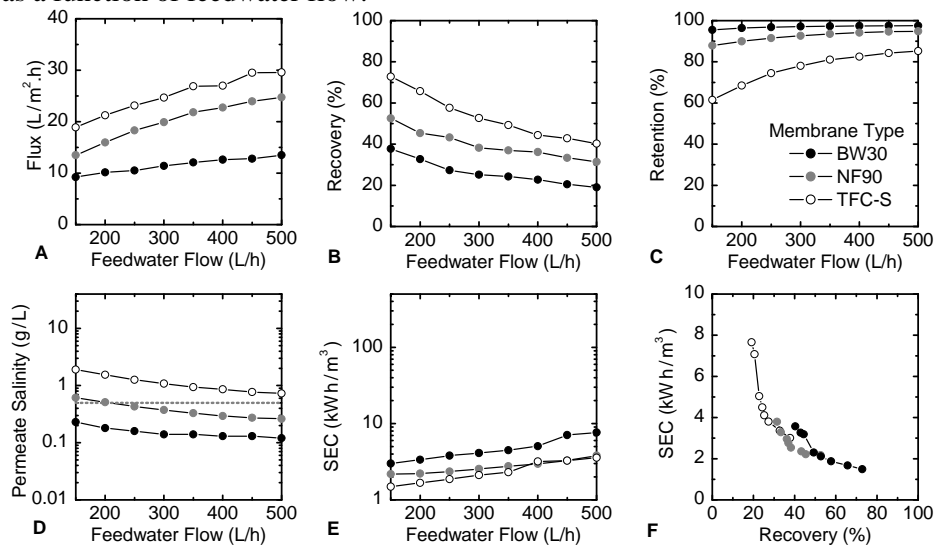

Figure 6. Performance of ROSI system when operated at a constant pressure of 10 bar for a wide range of feedwater flow rates $(150-500 \mathrm{~L} / \mathrm{h}, 5 \mathrm{~g} / \mathrm{L}$ TDS salinity), which is reflected in the recovery. The different curves correspond to the BW30 (-), NF90 (-) and TFC-4920-S (O) membranes: a) flux; b) recovery; c) retention; d) the resulting salinity in the permeate stream; e) specific energy consumption. In figure $6 f$ the variation of SEC is plotted as a function of recovery. The ADWG of $0.5 \mathrm{~g} / \mathrm{L} T D S$ is also plotted in grey in Figure $6 d$.

\section{DISCUSSION}

The performance of all three membranes used in these experiments was specified by the manufacturer at a recovery of 15\% (Dow Filmtec Membranes 2007a, 2007b; Koch Membrane Systems 2007). Often small-scale membrane filtration systems are designed such that the recovery would remain less than about 25\% (Laborde et al. 2001. Alajlan and Smiai, 1996, Keefer et al. 1985, Mathew et al. 2000, Weiner et al. 2001, Al Sulaeimani and Nair 2000) in order to prevent concentration polarization and increased fouling of the membrane (Laborde et al. 2001). In addition, recovery depends on the other factors such as, firstly, feedwater temperature, as the flux may increase by $2.7 \% /{ }^{\circ} \mathrm{C}$ rise in temperature (Alajlan and Smiai, 1996) and, secondly, the age and cleanliness of the membrane. Therefore, even in a system operated at constant pressure and flow, recovery will vary with time. As seen above, the recovery of the membrane modules used in this system varied significantly, due to the nature of the experiments in that pressure was varied in accordance with pump characteristics, and results show that a much broader range of recoveries can be tolerated in terms of water quality. Actual limitations are feedwater dependent as with very high recovery the risk of scaling may increase.

The BW30 membrane has the highest SEC for all feedwater salinities, the NF90 membrane the next lowest, while the TFC-S membrane exhibits the lowest SEC. This reflects the permeabilities of those membranes. However, a low SEC alone is not a good indication of satisfactory system performance, as the permeate salinity needs to be monitored as well. The BW30 membrane is able to desalinate 1 to $5 \mathrm{~g} / \mathrm{L}$ TDS feedwater at any operating pressure, while $7.5 \mathrm{~g} / \mathrm{L}$ TDS feedwater can only be desalinated to within the ADWG value of $0.5 \mathrm{~g} / \mathrm{L}$ for operating pressures of 8 bar or greater. The NF90 can also satisfactorily desalinate 1 to 
$5 \mathrm{~g} / \mathrm{L}$ TDS feedwater at any pressure, however higher feedwater salinities cannot be treated to meet the ADWG. Finally, while having the lowest SEC, the TFC-S membrane is only able to desalinate the lowest salinity feedwater $(1 \mathrm{~g} / \mathrm{L})$ at pressures of less than $12 \mathrm{bar}$ - all other feedwaters, the product water still contain more than $0.5 \mathrm{~g} / \mathrm{L}$ TDS. Therefore, the lower SEC achieved for higher feedwater salinities - for example, $1.8 \mathrm{kWh} / \mathrm{m}^{3}$ for $5 \mathrm{~g} / \mathrm{L}$ TDS - is not suitable unless a mu suitable uns Alajlan and Smiai 1996, Al Sulaeimani and Nair 2000), which is unrealistic in a developing country application thus the TFC-S membrane is most suitable for surface water treatment. The SEC increases with higher feed salt concentration, while it decreases with increasing applied pressure. There are two competing mechanisms at work here. On one hand, the SEC increases for higher salt concentrations as this increases the osmotic pressure, and thus more energy is required to overcome this natural pressure and to desalinate the water. On the other hand, the SEC is seen to decrease at higher applied pressures. The major effect here is that the permeate flux is increasing more rapidly than the power consumption, while the slight reduction of the salt intenton plays a minor tole (Masson et al. 2005). This suggests system should be able to be operated at a pressure which produces a maximum permeate flux and minimum SEC, and indeed this is seen for the TFC-S membrane for the lowest salinity feedwater. In general, the SEC of this system is acceptable for feedwater salinities of $7.5 \mathrm{~g} / \mathrm{L}$ TDS or less.

The increased permeate salinity can be attributed to reduced retention at higher transmembrane pressures, caused by high feedwater fluxes leading to reduced a crossflow velocity as recoveries approach $100 \%$. The increased boundary layer thickness that forms at high feedwater fluxes results in an increased diffusion of salt across the membrane. As discussed previously, operating the membranes at high recoveries is outside the nomal discussed peviously, op operating specification for the membranes, and this may have to be better controlled in the future.

For the experiments performed at constant pressure of $10 \mathrm{bar}$ and feedwater salinity of $5 \mathrm{~g} / \mathrm{L}$ TDS, the SEC (Figure 6e) increases at higher feedwater flows. This is understandable, as although a slightly higher flux is achieved at higher feedwater flows, much less water is recovered (see Figure 6b) and more the power consumption is many times greater (not plotted) and it is highest for the BW30 membrane and lowest for the TFC-4920-S membrane. The good overlap between the three curves in Figure $6 \mathrm{f}$ indicates that the SEC is primarily a function of membrane recovery and the system itself, rather than other effects such as A further interesting result that can now bo membrane is only able to meet the ADWG value for permeate salinity at a feetwer flow of greater than $250 \mathrm{~L} / \mathrm{h}$. However, it is believed that reduced flux at higher recoveries will result in the permeate salinity in the product tank maintaining an average that meets the ADWG value of $0.5 \mathrm{~g} / \mathrm{L}$ TDS. In contrast, the BW30 membrane is able to produce good quality permeate from the $5 \mathrm{~g} / \mathrm{L}$ feedwater at any recovery ratio (feedwater flow rate), albeit at a much higher SEC. Therefore, there is a trade-off in the optimum recovery for system design, with lower recoveries being favoured to avoid excessive concentration polarisation (Laborde et al. 2001), however this achieved only at a higher SEC. The results from this work suggest that a small-scale system equipped with the NF90 menthe is quite sultale operated autonomously from a fluctuating power source as it keeps the recovery ratio in the range $31-53 \%$ for those membranes tested.

\section{CONCLUSIONS}

Extensive optimization was performed on the ROSI system prototype in the laboratory for a wide range of feedwater salinities. It was found that the most appropriate membranes to treat different feedwater salinities are as follows: BW30 membrane for higher salinities $(7.5 \mathrm{~g} / \mathrm{L}$
TDS), the NF90 membrane for medium salinity brackish water (range $2.5-5 \mathrm{~g} / \mathrm{L}$ TDS), and the TFC-4920-S membrane for marginal (1 g/L TDS) feedwater. Feedwater salinities greater than $7.5 \mathrm{~g} / \mathrm{L}$ cannot be satisfactorily treated with this small-scale membrane treatment system due to pressure limitations of the pump). The best SEC for $5 \mathrm{~g} / \mathrm{L}$ TDS feedwater was $2.2 \mathrm{kWh} / \mathrm{m}^{3}$ using the NF90 membrane (at a pressure of 15 bar and a flow of $276 \mathrm{~L} / \mathrm{h}$ and of the ROSI system [Richards and Schäfer 2002, 2003]. It should be noted that no energy recovery system has been used in this system, however this could further reduce the SEC and should be investigated.

\section{ACKNOWLEDGMENTS}

Zenon Environmental (Canada), Dow Chemicals (Australia) and Koch Membrane Systems (USA) are thanked for the provision of membrane modules and/or technical support. Funding for this project is provided through the Australian Research Council Linkage Projects scheme (LP0349322). The authors would like to thank Andrew Moore from Mono Pumps (Australia) for useful discussions and project support.

\section{REFERENCES}

Alajlan, S.A., Smiai, M.S., 1996. Performance and development of PV-plant for water pumping and desalination for remote areas in Saudi Arabia, In: Proc. of World Renewable Energy Congress IV, Denver, Colorado, USA, pp. 441-446.

Al Suleimani, Z., Nair, V.R., 2000. Desalination by solar-powered reverse osmosis in a remote area of the Sultanate of Oman. Applied Energy 65, 367-380.

Block, D.L., Melody, I.I., 1989. Assessment of Solar Desalination Processess. In: Proc. of Solar '89, American Solar Energy Society, Denver, USA, pp.62-71.

Côté, P., Coburn, J., Munro, A., 2001. A new immersed membrane for pretreatment to reverse osmosis. Desalination 139, 229-236.

Crutcher, J.L., Norbedo, A.J., Cummings, A.B., 1982. Photovoltaic powered seawater desalination systems: experience with two installations. In: Proc. $16^{\text {th }}$ IEEE Photovoltaics Specialists Conference, pp. 1400-1404.

Dow Filmtec Membranes, 2007. BW30 technical information. URL: http://www.dow.com/PublishedLiterature/dh_058e/09002f138058eb00.pdf (last accessed 28 Feb 2007).

Dow Filmtec Membranes, 2007. NF90 technical information. URL: http://www.dow.com/PublishedLiterature/dh_0603/09002f13806035f5.pdf (last accessed 28 Feb 2007).

Keefer, B.G., Hembree, R.D., Schrack, F.C., 1985. Optimized matching of solar photovoltaic power with reverse osmosis desalination, Desalination 54, 89-103.

Koch Membrane Systems, 2007. TFC-S technical information.

URL : http://www.kochmembrane.com/pdf/8492000spiral.pdf (last accessed 28 Feb 2007).

Laborde, H.M., França, K.B., Neff, H., Lima, A.M.N., 2001, Optimization strategy for smallscale reverse osmosis water desalination system based on solar energy, Desalination 133, $1-12$.

Masson, L., Richards, B.S., Schäfer, A.I., 2005. System design and performance testing of a hybrid membrane photovoltaic desalination system. Desalination 179, 51-59.

Mathew, K., Dallas, S., Ho, G.E., Anda M., 2000. A Solar-Powered Village Water Supply System From Brackish Water, In: Proc. of World Renewable Energy Congress VI, Brighton, U.K, pp. 2061-2064.

National Health and Medical Research Council (NHMRC) 2004. Australian Drinking Water Guidelines, National Health and Medical Research Council, National Water Quality 
Management Strategy, 2004.

Parodi O., Preiser, K., Schweizer-Ries, P., 2000. Clean water with clean energy: A huge market for PV - but not yet explored. In: Proc. of $16^{\text {th }}$ European Photovoltaic Solar Energy Conference. pp. 2997-3001.

Redondo, J.A., 2001. Brackish-, sea- and wastewater desalination, Desalination 138, 29-40.

Richards, B.S., Schäfer, A.I., 2003. Photovoltaic-powered desalination system for remote Australian communities. Renewable Energy 28, 2013-2022.

Richards, B.S., Schäfer, A.I., 2002. Design considerations for a solar-powered desalination system for remote communities in Australia. Desalination 144, 193-199.

Schäfer, A.I., Broeckmann, A., Richards, B.S., 2007. Renewable energy powered membrane technology. 1. Development and characterization of a photovoltaic hybrid membrane system, Environmental Science \& Technology, 41: 998-1003.

Schäfer, A.I., Richards, B.S., 2007. From Concept to Commercialization: Student Learning in a Sustainable Engineering Innovation Project, European Journal of Engineering Education, 32(2): 1-23.

United Nations Development (UNDP) Report, 1998. Human Development Report, Goetzky, Bonn, Germany.

J. Vrba, B.T. Verhagen, Groundwater for emergency situations - A framework document, International Hydrological Programme VI, Series on Groundwater No. 12, UNESCO, Paris 2006, URL: http://unesdoc.unesco.org/images/0014/001427/142762e.pdf

Weiner, D., Fisher, D., Moses, E.J., Katz, B., Meron, G., 2001. Operation experience of a solar- and wind-powered desalination demonstration plant. Desalination 137, 7-13. 